\title{
Increased Mercury Levels in Patients with Celiac Disease following a Gluten-Free Regimen
}

\author{
Luca Elli, ${ }^{1}$ Valentina Rossi, ${ }^{1,2}$ Dario Conte, ${ }^{1}$ Anna Ronchi, ${ }^{3}$ Carolina Tomba, ${ }^{1}$ \\ Manuela Passoni, ${ }^{2}$ Maria Teresa Bardella, ${ }^{1}$ Leda Roncoroni, ${ }^{1,4}$ and Gianpaolo Guzzi ${ }^{2}$ \\ ${ }^{1}$ Center for the Prevention and Diagnosis of Celiac Disease, Gastroenterology and Endoscopy Unit, \\ Fondazione IRCCS Ca' Granda Ospedale Maggiore Policlinico, Department of Pathophysiology and Transplantation, \\ Università degli Studi di Milano, Via Francesco Sforza 35, 20122 Milan, Italy \\ ${ }^{2}$ Italian Association for Metals and Biocompatibility Research (AIRMEB), Via Banfi 4, 20122 Milan, Italy \\ ${ }^{3}$ Pavia Poison Control Center and National Toxicology Information Centre, Toxicology Unit, \\ IRCCS Maugeri Foundation and University of Pavia, Via Salvatore Maugeri 10, 27100 Pavia, Italy \\ ${ }^{4}$ Department of Biomedical, Surgical and Dental Sciences, Università degli Studi di Milano, Via Festa del Perdono 7, 20122 Milan, Italy
}

Correspondence should be addressed to Luca Elli; lucelli@yahoo.com

Received 9 November 2014; Accepted 2 February 2015

Academic Editor: Paul Enck

Copyright (C) 2015 Luca Elli et al. This is an open access article distributed under the Creative Commons Attribution License, which permits unrestricted use, distribution, and reproduction in any medium, provided the original work is properly cited.

\begin{abstract}
Background and Aim. Although mercury is involved in several immunological diseases, nothing is known about its implication in celiac disease. Our aim was to evaluate blood and urinary levels of mercury in celiac patients. Methods. We prospectively enrolled 30 celiac patients (20 treated with normal duodenal mucosa and 10 untreated with duodenal atrophy) and 20 healthy controls from the same geographic area. Blood and urinary mercury concentrations were measured by means of flow injection inductively coupled plasma mass spectrometry. Enrolled patients underwent dental chart for amalgam fillings and completed a food-frequency questionnaire to evaluate diet and fish intake. Results. Mercury blood/urinary levels were 2.4 $\pm 2.3 / 1.0 \pm 1.4,10.2 \pm 6.7 / 2.2 \pm 3.0$ and $3.7 \pm 2.7 / 1.3 \pm 1.2$ in untreated CD, treated CD, and healthy controls, respectively. Resulting mercury levels were significantly higher in celiac patients following a gluten-free diet. No differences were found regarding fish intake and number of amalgam fillings. No demographic or clinical data were significantly associated with mercury levels in biologic samples. Conclusion. Data demonstrate a fourfold increase of mercury blood levels in celiac patients following a gluten-free diet. Further studies are needed to clarify its role in celiac mechanism.
\end{abstract}

\section{Introduction}

Mercury (Hg) is ubiquitous environmental heavy metal, naturally originating from erosion of the volcanic rocks and accumulating in the food chain. Besides its natural presence, $\mathrm{Hg}$ environmental concentration is progressively increasing due to its employ in human industry and manufactures (medications, thermometers, blood-pressure cuffs, batteries, switches, and fluorescent light bulbs) [1-4]. Thus, $\mathrm{Hg}$ is actually considered a pollutant and, due to its deleterious effects on humans, it is generally considered toxic especially for the nervous system [5]. Mercury main sources for human being are represented by fish consumption, dental amalgams, and vaccines $[4,6]$. Once in the body, $\mathrm{Hg}$ atoms bind the proteic thiol groups and deposit in all tissues, where they can remain for a long time, triggering its chronic consequences on health $[7,8]$; in fact, behind the $\mathrm{Hg}$ acute intoxication syndrome (exemplified by Minamata Bay disaster) [9], recent scientific advances have demonstrated that $\mathrm{Hg}$ is a cofactor in several multifactorial diseases (cardiovascular, neurodegenerative, and autoimmune), as a consequence of its biological effect on inflammation and immune system $[1,10-14]$. Hg is mainly an HLA class IIrestricted immunostimulator, leading to the proliferation of $\mathrm{B}$ and $\mathrm{T}$ lymphocytes and formation of autoantibodies and immunocomplexes [15]. In the last decades, the concomitant increase of autoimmune disorders and $\mathrm{Hg}$ environmental pollution represents an intriguing point [16]. In particular, 
the hypothesis of $\mathrm{Hg}$-autoimmunity connection appears plausible for disorders characterized by a HLA restricted genetic background $[17,18]$ as celiac disease (CD), an HLA class II-dependent autoimmune disease of the small bowel [19-21]. CD is a common (prevalence rate 1:100) chronic enteropathy triggered, in genetically predisposed subjects (carrying the HLA DQ2 and/or DQ8 haplotypes), by the ingestion of gluten $[19,22,23]$. In CD, gluten induces and fuels an immunological response inducing a small bowel mucosa damage characterized by intraepithelial lymphocytosis, crypt hyperplasia, and villous atrophy [24]. However, other-than-gluten environmental factors are supposed to be present in the development of CD. Among them, infectious agents (virus) [25] and microbiota [26] have been evaluated without conclusive data.

In this context, considering the absence of pertinent findings, $\mathrm{Hg}$ role in the $\mathrm{CD}$ pathomechanism could be hypothesized.

The present study aimed to evaluate the Hg levels in CD patients.

\section{Materials and Methods}

2.1. Patients. From January 1, 2007, to June 6, 2010, subjects signing an informed consent were consecutively and prospectively enrolled at the "Center for Prevention and Diagnosis of Celiac Disease" of the "Fondazione IRCCS Ca' Granda Ospedale Maggiore Policlinico," Milan, Italy. CD diagnosis was based on the presence of serological anti-tissue transglutaminase (tTGA, ELISA, or radioimmunoassay tests) and/or anti-endomisium (EmA, immunofluorescence technique) IgA antibodies and a duodenal histology presenting villous atrophy (grade 3 according to the Marsh-Oberhuber classification) [27]. The enrolment included both newly diagnosed and treated (following a gluten-free diet, GFD) CD patients. Treated CD patients were compliant to the GFD with normalization of serological tests and restoration of the duodenal villous architecture (grade 0 according to the Marsh-Oberhuber classification). A group of nonCD subjects was enrolled as controls. Patients reporting an occupational exposure to $\mathrm{Hg}$ were excluded such as patients reporting renal or liver pathologies. To avoid environmental pollution differences, all participants were resident in the same urban area (Milan, Northern Italy).

Enrolled patients underwent an odontostomatologic visit to evaluate dental amalgam fillings and completed an operator assisted questionnaire investigating the intake of potential $\mathrm{Hg}$ containing food (fish, days of intake/month), the presence of possible factors influencing the $\mathrm{Hg}$ levels (nocturnal bruxism, chewing gum use in presence of $\mathrm{Hg}$ amalgams), and the presence of symptoms possibly correlated with $\mathrm{Hg}$ exposure (metallic taste, foggy mind, chronic fatigue, and tremor) [28]. Moreover, a detailed seven-day alimentary diary was completed by participants.

The study was approved by the ethical committee of the "Fondazione IRCCS Ca' Granda Ospedale Maggiore Policlinico."

2.2. Mercury Analysis of Biological Samples. Total Hg levels were assessed by using flow injection inductively coupled plasma

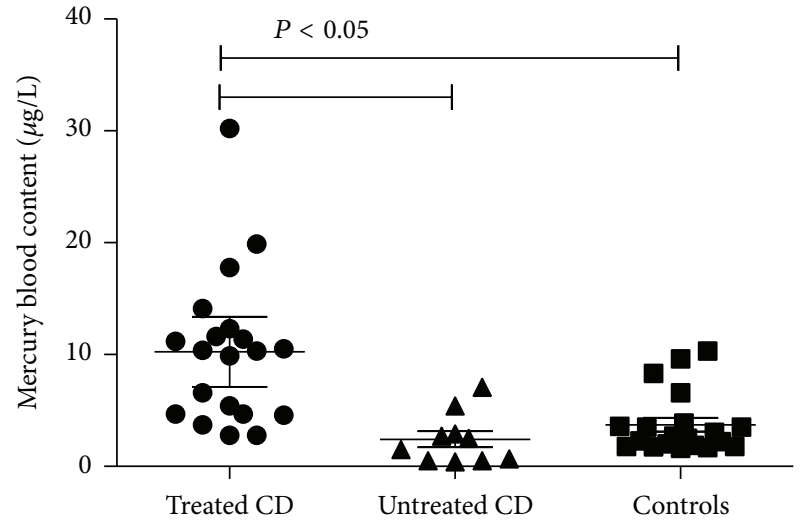

Figure 1: Mercury (Hg) blood levels of untreated and treated celiac (CD) patients and healthy controls. Mean, $95 \%$ confidence intervals, and statistical significance are reported in the plot.

mass spectrometry (FI-ICP-MS) as previously described [29, 30]. Briefly, at enrollment, fasting morning venous peripheral whole blood samples $(4 \mathrm{~mL})$ were collected in $\mathrm{Hg}$ free polypropylene tubes containing potassium EDTA, as an anticoagulant. First morning urine specimens (100 milliliters) were obtained and stored at $+4^{\circ} \mathrm{C}$ until mercury analysis. Both blood and urine samples were delivered immediately to the laboratory of toxicology for FI-ICP-MS Hg analysis and were processed within 24-72 hours after collection. The limit of detection was 0.05 micrograms per liter. Internal and external quality-control procedures were done.

2.3. Statistical Analysis. All the assumptions were verified using SPSS version 18 (IBM SPSS, Italy), and a $P$ value $<0.05$ was considered statistically significant (significance level of the tests 5\%, two tails). Continuous variables were analyzed with the ANOVA one-way variance test, Turkey's test, or the nonparametric Kruskal-Wallis test when indicated. Categorical variables were compared by $\chi^{2}$ or Fisher's exact test. Kolmogorov-Smirnov was used to assess Gaussian distribution of the data. Correlations were analysed by Pearson or Spearman test in case of Gaussian or nonparametric variables.

\section{Results}

Thirty CD patients (20 treated and 10 untreated) and 20 healthy controls were enrolled. As shown in Table 1, patient age, sex, weight, and height (body mass index, BMI) were not statistically different among the three investigated groups.

Details of blood and urinary $\mathrm{Hg}$ levels of the analysed groups are reported in Table 2. Mercury blood levels resulting significantly increased in treated CD patients compared to untreated CD, as detailed in Figure 1.

The number of $\mathrm{Hg}$ amalgam fillings was $5.0 \pm 2.9,3.0 \pm$ 2.8 , and $3.8 \pm 2.6$ in untreated $\mathrm{CD}$, treated $\mathrm{CD}$, and healthy controls, respectively, without a statistical difference among the groups. The number of amalgam fillings was unrelated to both blood and urinary $\mathrm{Hg}$ levels (unreported data). Bruxism prevalence and chewing gum use were comparable in the three aforementioned groups (five, nine, and ten cases 
TABLE 1: Clinical and demographic parameters of the enrolled subjects.

\begin{tabular}{|c|c|c|c|c|}
\hline & Untreated CD $(n=10)$ & Treated CD $(n=20)$ & Healthy controls $(n=20)$ & $P$ \\
\hline Age (years) & $40.4 \pm 7.5$ & $40.1 \pm 9.7$ & $39.6 \pm 10.9$ & NS \\
\hline Male/female & $3 / 7$ & $3 / 17$ & $4 / 16$ & NS \\
\hline Weight (Kg) & $57.0 \pm 11.2$ & $60.2 \pm 8.4$ & $62.1 \pm 10.4$ & NS \\
\hline Height $(\mathrm{cm})$ & $167.7 \pm 5.0$ & $165.7 \pm 6.6$ & $169.8 \pm 9.0$ & NS \\
\hline BMI & $20.2 \pm 3.6$ & $21.9 \pm 3.0$ & $21.8 \pm 2.8$ & NS \\
\hline tTGA (positive \%) & 100 & 0 & 0 & NA \\
\hline Villous atrophy (Pts \%) & 100 & 0 & 0 & NA \\
\hline GFD (years) & NA & $8.2 \pm 8.2$ & NA & NA \\
\hline
\end{tabular}

BMI: body mass index; CD: celiac disease; NS: not significant; NA: not applicable; GFD: gluten-free diet; tTGA; tissue transglutaminase antibodies; Pts: patients.

TABLE 2: Urinary and blood mercury (Hg) levels in celiac patients and healthy controls.

\begin{tabular}{lccc}
\hline & $\begin{array}{c}\text { Untreated CD } \\
(n=10)\end{array}$ & $\begin{array}{c}\text { Treated CD } \\
(n=20)\end{array}$ & $\begin{array}{c}\text { Healthy controls } \\
(n=20)\end{array}$ \\
\hline Hg blood $(\mu \mathrm{g} / \mathrm{L})$ & $2.4 \pm 2.3$ & $10.2 \pm 6.7^{*}$ & $3.7 \pm 2.7$ \\
Hg urine $(\mu \mathrm{g} / \mathrm{L})$ & $1.0 \pm 1.4$ & $2.2 \pm 3.0$ & $1.3 \pm 1.2$ \\
\hline
\end{tabular}

CD: celiac disease; Hg: mercury.

${ }^{*} \mathrm{P}<0.05$ versus $\mathrm{Hg}$ blood levels of untreated $\mathrm{CD}$ and healthy controls.

affected by bruxism and two, three, and four chewing gum users in untreated $\mathrm{CD}$, treated $\mathrm{CD}$, and healthy controls, resp.).

A part from for the presence of gluten-free products in the diet of treated CD, the weekly intake of fish and seafood, nonalcoholic beverages, and composite food (i.e., the main sources of dietary $\mathrm{Hg}$ ), as obtained from the seven-day long questionnaire, was comparable in the studied groups and did not correlate with the $\mathrm{Hg}$ levels in both blood and urine. In particular the fish intake ranged from 3 to 4 times per week in the investigated groups (data not shown).

As showed in Figure 1, the group of treated CD patients could be divided into two subgroups, the first composed of 11 patients with $\mathrm{Hg}$ blood levels $\geq 10 \mu \mathrm{g} / \mathrm{L}$ and the second composed of 9 patients with blood $\mathrm{Hg}$ levels $<10 \mu \mathrm{g} / \mathrm{L}$. Among treated CD patients with $\mathrm{Hg}$ blood levels $\geq 10 \mu \mathrm{g} / \mathrm{L}$, metallic taste was reported by $36 \%$ of subjects versus $33 \%$ of patients with $\mathrm{Hg}$ blood levels $<10 \mu \mathrm{g} / \mathrm{L}$, foggy mind $45 \%$ versus $11 \%$, chronic fatigue $18 \%$ versus $0 \%$, and tremor $27 \%$ versus $22 \%$. Although the above Hg-related symptoms were increased in group with blood $\mathrm{Hg}$ levels $\geq 10 \mu \mathrm{g} / \mathrm{L}$, differences were not statistically significant probably due to the limited number of cases.

\section{Discussion}

The present study demonstrated an increase of $\mathrm{Hg}$ levels in patients affected by CD following a GFD. This finding, presented here for the first time, deserves some comments and considerations.

As for many other autoimmune diseases, CD prevalence is increasing in the last decade $[16,31]$. In the past, $C D$ was considered a rare disorder of childhood, characterised by malabsorption and growth deficiency [32]; nowadays, it is the most frequent autoimmune chronic enteropathy $(1: 100)$ in western countries and it can be diagnosed at every age $[19,33,34]$. This "pandemia" is partially explained by the improvement of diagnostic tests (ELISA commercial kits for detection of anti-tissue transglutaminase antibodies) and digestive endoscopy worldwide diffusion. A "real" CD increase seems demonstrated by studies based on biobanked biologic samples $[35,36]$. This finding is difficult to explain but it is clear that unknown environmental factors are involved as suggested by studies on monozygotic twins demonstrating $80 \%$ concordance rate for the development of CD [37]. Celiac disease pathogenetic cascade is started by an activation of mucosal $\mathrm{T}$ cells, leading to a chronic autoimmune reaction responsible for the typical duodenal damage with T cell infiltration, crypt hyperplasia, and villous atrophy [38]. This mechanism occurs exclusively in the presence of the HLA DQ2 and/or DQ8 haplotypes [38]. During the last years, different researchers investigated factors potentially stimulating the onset of an overt CD or simply increasing its risk [25, 39-41]. Previous studies investigated breast feeding habit [42], virus infection (rotavirus) [25], and the intake of high gluten-containing grain or the use of enzymes (bacterial transglutaminases) in food industry [23], without conclusive data. No environmental pollutant or toxicants have been investigated in $\mathrm{CD}$, although environmental pollution is getting higher and higher in the last decades. Different studies demonstrated that $\mathrm{Hg}$ participates in the development of several immune disorders as membraneous nephropathy [43], autoimmune glomerulonephritis [44], Wegener's granulomatosis [45], scleroderma [46], systemic lupus erythematosus [47], pemphigus [48], and multiple sclerosis [49]. Epidemiologic data suggest that $\mathrm{Hg}$ amalgam fillings have an effect in the exacerbation and/or onset of multiple sclerosis [47]. This connection is strengthened by the clinical improvements reported by patients affected by Hashimoto's thyroiditis after $\mathrm{Hg}$ amalgam fillings removal [47]. Again, $\mathrm{Hg}$ induces in humans the formation of different types of autoantibodies (antinuclear, antinucleolar, anti-fibrillarin, and anti-laminin) and its effect is particularly relevant in diseases controlled by the major histocompatibility complex (MHC) class II (as CD), although these data mainly come from animal studies $[1,13,50]$.

Another important point is represented by the increase of $\mathrm{Hg}$ levels after duodenal mucosa normalization in treated CD. This finding represents the first demonstration that 
duodenal atrophy could lead to a reversible Hg "malabsorption." Actually, very few are known about the Hg transport/absorption in human small bowel. Recent in vitro data on Caco-2 cell line suggest the existence of an active $\mathrm{Hg}$ transport into enterocytes although the transporter remains unknown [51]. This "scenario" could be comparable to that observed for iron intestinal transport when a genetically determined hemochromatosis is present in association with $\mathrm{CD}$ : the concomitant duodenal atrophy preserves patients by iron overload and the development of clinically relevant hemochromatosis, usually developing during the GFD (i.e., duodenal normalization) $[52,53]$. Interpretation of the present finding leads to important observations: (i) intestinal $\mathrm{Hg}$ absorption is mainly localized in the duodenum; (ii) $\mathrm{Hg}$ seems to be absorbed by transporters mainly localised on the apical part of the villi, typically damaged in CD. However, another factor increasing the $\mathrm{Hg}$ levels could be the GFD itself; in fact, GFD could have a positive effect favoring the $\mathrm{Hg}$ release from the intracellular stores to extracellular fluids (i.e., blood). If this process could be related to the presence of symptoms (metallic taste, foggy mind, chronic fatigue, and tremor) resembling $\mathrm{Hg}$ poisoning as detected in our cohort, it remains an interesting point to be investigated in large series of patients.

The relevant increase of Hg blood levels in treated CD is not justified by differences in seafood consumption and dental amalgam fillings, which are considered important sources of $\mathrm{Hg}$ for humans by the World Health Organization, WHO [11]. Fish generally accumulates $\mathrm{Hg}$ through the alimentary chain and for these reasons fish-eating fishes (swordfish, tuna, etc.) are more likely $\mathrm{Hg}$-contaminated, while amalgam fillings continuously release $\mathrm{Hg}$ in the mouth, especially in patients affected by bruxism or using chewing gum [11].

Looking at these data, $\mathrm{Hg}$ accumulation could also be due to a genetic predisposition of $\mathrm{CD}$ subjects to retain it (see also low Hg levels in urine). In our study we analysed whole blood and urine $\mathrm{Hg}$ levels, believed to be reliable marker for $\mathrm{Hg}$ exposure; however this choice could have some implications. When exposure continues, tissue levels of $\mathrm{Hg}$ in humans are increased, mainly in brain (pituitary gland and cerebral cortex), central nervous system, thyroid, and kidneys. Hence, concentrations of $\mathrm{Hg}$ in blood and urine may underestimate retention of $\mathrm{Hg}$ in the organism. In other words, there is the possibility that measurements of $\mathrm{Hg}$ in blood and urine do not fully reflect the real body content.

Another limitation of the study, besides the limited number of patients, is that blood and urine $\mathrm{Hg}$ concentrations not always correlate with the noxious effects in humans. In fact, response to $\mathrm{Hg}$ is influenced by different factors inducing the onset of the immune or neurologic alteration. These factors are largely unknown but genetic ones are the strongly suspected: subjects with a predisposition to accumulate $\mathrm{Hg}$ in determined cells or tissues could be more susceptible to specific toxic effects [4].

In conclusion, our study demonstrates an alteration of $\mathrm{Hg}$ content in CD when a gluten-free regimen is followed. This result could be due to an altered response to $\mathrm{Hg}$ exposure, with the tendency to accumulate it. Further studies are needed to clarify if $\mathrm{CD}$ genetic background could generate "sensitivity" to Hg proinflammatory effect and inspire new rules for the surveillance of $\mathrm{Hg}$ content in food.

\section{Conflict of Interests}

The authors declare that there is no conflict of interests regarding the publication of this paper.

\section{Acknowledgment}

The study was supported by "Fondazione IRCCS Ca' Granda Ospedale Maggiore Policlinico, Milano.”

\section{References}

[1] T. W. Clarkson, "The three modern faces of mercury," Environmental Health Perspectives, vol. 110, supplement 1, pp. 11-23, 2002.

[2] K. Suresh Kumar Reddy, A. Al Shoaibi, and C. Srinivasakannan, "Elemental mercury adsorption on sulfur-impregnated porous carbon-a review," Environmental Technology, vol. 35, no. 1, pp. 18-26, 2014.

[3] R. D. Day, P. R. Becker, O. F. X. Donard, R. S. Pugh, and S. A. Wise, "Environmental specimen banks as a resource for mercury and mercury isotope research in marine ecosystems," Environmental Sciences: Processes and Impacts, vol. 16, no. 1, pp. $10-27,2014$.

[4] S. M. Koral, "The toxicology of mercury," The New England Journal of Medicine, vol. 350, no. 9, pp. 945-947, 2004.

[5] C. Sanfeliu, J. Sebastià, and S. U. Kim, "Methylmercury neurotoxicity in cultures of human neurons, astrocytes, neuroblastoma cells," NeuroToxicology, vol. 22, no. 3, pp. 317-327, 2001.

[6] S. M. Koral, "Mercury from dental amalgam: exposure and risk assessment," Compendium of Continuing Education in Dentistry, vol. 34, no. 2, pp. 138-144, 2013.

[7] J. D. Park and W. Zheng, "Human exposure and health effects of inorganic and elemental mercury," Journal of Preventive Medicine and Public Health, vol. 45, no. 6, pp. 344-352, 2012.

[8] X. Xu, C. Mathieu, S. E. Boitard et al., "Skeletal muscle glycogen phosphorylase is irreversibly inhibited by mercury: molecular, cellular and kinetic aspects," FEBS Letters, vol. 588, no. 1, pp. 138-142, 2014.

[9] S. Ekino, M. Susa, T. Ninomiya, K. Imamura, and T. Kitamura, "Minamata disease revisited: an update on the acute and chronic manifestations of methyl mercury poisoning," Journal of the Neurological Sciences, vol. 262, no. 1-2, pp. 131-144, 2007.

[10] K. K. Aminzadeh and M. Etminan, "Dental amalgam and multiple sclerosis: a systematic review and meta-analysis," Journal of Public Health Dentistry, vol. 67, no. 1, pp. 64-66, 2007.

[11] G. Guzzi, G. B. Fogazzi, M. Cantu et al., "Dental amalgam, mercury toxicity, and renal autoimmunity," Journal of Environmental Pathology, Toxicology and Oncology, vol. 27, no. 2, pp. 147-155, 2008.

[12] C.-C. Kuo, K. Moon, K. A. Thayer, and A. Navas-Acien, "Environmental chemicals and type 2 diabetes: an updated systematic review of the epidemiologic evidence," Current Diabetes Reports, vol. 13, no. 6, pp. 831-849, 2013.

[13] J. F. Nyland, M. Fillion, F. Barbosa Jr. et al., "Biomarkers of methylmercury exposure immunotoxicity among fish consumers in amazonian Brazil," Environmental Health Perspectives, vol. 119, no. 12, pp. 1733-1738, 2011. 
[14] G. Guzzi and C. A. M. La Porta, "Molecular mechanisms triggered by mercury," Toxicology, vol. 244, no. 1, pp. 1-12, 2008.

[15] S. Havarinasab, E. Björn, J. Ekstrand, and P. Hultman, "Dose and $\mathrm{Hg}$ species determine the T-helper cell activation in murine autoimmunity," Toxicology, vol. 229, no. 1-2, pp. 23-32, 2007.

[16] D. L. Jacobson, S. J. Gange, N. R. Rose, and N. M. H. Graham, "Epidemiology and estimated population burden of selected autoimmune diseases in the United States," Clinical Immunology and Immunopathology, vol. 84, no. 3, pp. 223-243, 1997.

[17] P. Hultman and H. Hansson-Georgiadis, "Methyl mercuryinduced autoimmunity in mice," Toxicology and Applied Pharmacology, vol. 154, no. 3, pp. 203-211, 1999.

[18] P. Moszczynski, S. Slowinski, J. Rutkowski, S. Bem, and D. JakusStoga, "Lymphocytes, T and NK cells, in men occupationally exposed to mercury vapours," International Journal of Occupational Medicine and Environmental Health, vol. 8, no. 1, pp. 4956, 1995.

[19] A. Fasano and C. Catassi, "Celiac disease," The New England Journal of Medicine, vol. 367, no. 25, pp. 2419-2426, 2012.

[20] N. Gujral, H. J. Freeman, and A. B. R. Thomson, "Celiac disease: prevalence, diagnosis, pathogenesis and treatment," World Journal of Gastroenterology, vol. 18, no. 42, pp. 60366059, 2012.

[21] P. Nijeboer, R. L. J. van Wanrooij, G. J. Tack, C. J. J. Mulder, and G. Bouma, "Update on the diagnosis and management of refractory coeliac disease," Gastroenterology Research and Practice, vol. 2013, Article ID 518483, 9 pages, 2013.

[22] M. T. Bardella, L. Elli, S. D. Matteis, I. Floriani, V. Torri, and L. Piodi, "Autoimmune disorders in patients affected by celiac sprue and inflammatory bowel disease," Annals of Medicine, vol. 41, no. 2, pp. 139-143, 2009.

[23] L. Elli, V. Discepolo, M. T. Bardella, and S. Guandalini, "Does gluten intake influence the development of celiac diseaseassociated complications?" Journal of Clinical Gastroenterology, vol. 48, no. 1, pp. 13-20, 2014.

[24] L. Elli, C. M. Bergamini, M. T. Bardella, and D. Schuppan, "Transglutaminases in inflammation and fibrosis of the gastrointestinal tract and the liver," Digestive and Liver Disease, vol. 41, no. 8, pp. 541-550, 2009.

[25] P. Pavone, E. Nicolini, R. Taibi, and M. Ruggieri, "Rotavirus and celiac disease," The American Journal of Gastroenterology, vol. 102, no. 8, article 1831, 2007.

[26] E. Sánchez, I. Nadal, E. Donat, C. Ribes-Koninckx, M. Calabuig, and Y. Sanz, "Reduced diversity and increased virulence-gene carriage in intestinal enterobacteria of coeliac children," BMC Gastroenterology, vol. 8, article 50, 2008.

[27] G. Oberhuber, G. Granditsch, and H. Vogelsang, "The histopathology of coeliac disease: time for a standardized report scheme for pathologists," European Journal of Gastroenterology and Hepatology, vol. 11, no. 10, pp. 1185-1194, 1999.

[28] C. Cooksey, "Health concerns of heavy metals and metalloids," Science Progress, vol. 95, no. 1, pp. 73-88, 2012.

[29] P. D. Pigatto, C. Minoia, A. Ronchi et al., "Allergological and toxicological aspects in a multiple chemical sensitivity cohort," Oxidative Medicine and Cellular Longevity, vol. 2013, Article ID 356235, 12 pages, 2013.

[30] P. Apostoli, I. Cortesi, A. Mangili et al., "Assessment of reference values for mercury in urine: the results of an Italian polycentric study," Science of the Total Environment, vol. 289, no. 1-3, pp. 13-24, 2002.
[31] M. D. Mayes, "Epidemiologic studies of environmental agents and systemic autoimmune diseases," Environmental Health Perspectives, vol. 107, supplement 5, pp. 743-748, 1999.

[32] S. G. Cole and M. F. Kagnoff, "Celiac disease," Annual Review of Nutrition, vol. 5, pp. 241-266, 1985.

[33] L. Elli and M. T. Bardella, "Motility disorders in patients with celiac disease," Scandinavian Journal of Gastroenterology, vol. 40, no. 7, pp. 743-749, 2005.

[34] P. H. R. Green and B. Jabri, "Coeliac disease," The Lancet, vol. 362, no. 9381, pp. 383-391, 2003.

[35] S. Lohi, K. Mustalahti, K. Kaukinen et al., "Increasing prevalence of coeliac disease over time," Alimentary Pharmacology and Therapeutics, vol. 26, no. 9, pp. 1217-1225, 2007.

[36] K. Mustalahti, C. Catassi, A. Reunanen et al., "The prevalence of celiac disease in Europe: results of a centralized, international mass screening project," Annals of Medicine, vol. 42, no. 8, pp. 587-595, 2010.

[37] L. Nisticò, C. Fagnani, I. Coto et al., "Concordance, disease progression, and heritability of coeliac disease in Italian twins," Gut, vol. 55, no. 6, pp. 803-804, 2006.

[38] D. Schuppan, Y. Junker, and D. Barisani, "Celiac disease: from pathogenesis to novel therapies," Gastroenterology, vol. 137, no. 6, pp. 1912-1933, 2009.

[39] L. M. Sollid and B. Jabri, "Triggers and drivers of autoimmunity: lessons from coeliac disease," Nature Reviews Immunology, vol. 13, no. 4, pp. 294-302, 2013.

[40] L. Elli, E. Dolfini, and M. T. Bardella, "Gliadin cytotoxicity and in vitro cell cultures," Toxicology Letters, vol. 146, no. 1, pp. 1-8, 2003.

[41] J. F. Ludvigsson, S. M. Montgomery, and A. Ekbom, "Smoking and celiac disease: a population-based cohort study," Clinical Gastroenterology and Hepatology, vol. 3, no. 9, pp. 869-874, 2005.

[42] L. Å. Persson, A. Ivarsson, and O. Hernell, "Breast-feeding protects against celiac disease in childhood-epidemiological evidence," Advances in Experimental Medicine and Biology, vol. 503, pp. 115-123, 2002.

[43] R. R. Tubbs, G. N. Gephardt, J. T. McMahon et al., "Membranous glomerulonephritis associated with industrial mercury exposure. Study of pathogenetic mechanisms," American Journal of Clinical Pathology, vol. 77, no. 4, pp. 409-413, 1982.

[44] S. Miller, S. Pallan, A. S. Gangji, D. Lukic, and C. M. Clase, "Mercury-associated nephrotic syndrome: a case report and systematic review of the literature," The American Journal of Kidney Diseases, vol. 62, no. 1, pp. 135-138, 2013.

[45] D. Albert, C. Clarkin, J. Komoroski, C. M. Brensinger, and J. A. Berlin, "Wegener's granulomatosis: possible role of environmental agents in its pathogenesis," Arthritis Care \& Research, vol. 51, no. 4, pp. 656-664, 2004.

[46] F. C. Arnett, M. J. Fritzler, C. Ahn, and A. Holian, "Urinary mercury levels in patients with autoantibodies to U3-RNP (fibrillarin)," Journal of Rheumatology, vol. 27, no. 2, pp. 405410, 2000.

[47] J. Prochazkova, I. Sterzl, H. Kucerova, J. Bartova, and V. D. M. Stejskal, "The beneficial effect of amalgam replacement on health in patients with autoimmunity," Neuroendocrinology Letters, vol. 25, no. 3, pp. 211-218, 2004.

[48] A. M. Abréu Vélez, G. Warfvinge, W. L. Herrera et al., "Detection of mercury and other undetermined materials in skin biopsies of endemic pemphigus foliaceus," The American Journal of Dermatopathology, vol. 25, no. 5, pp. 384-391, 2003. 
[49] A. M. Attar, A. Kharkhaneh, M. Etemadifar, K. Keyhanian, V. Davoudi, and M. Saadatnia, "Serum mercury level and multiple sclerosis," Biological Trace Element Research, vol. 146, no. 2, pp. 150-153, 2012.

[50] P. D. Pigatto, C. Minoia, L. Brambilla, S. Ferrucci, and G. Guzzi, "Auto-antibodies to nuclear and nucleolar antigen and longterm exposure to inorganic mercury," Environmental Research, vol. 110, no. 8, article 821, 2010.

[51] M. Vázquez, M. Calatayud, D. Vélez, and V. Devesa, "Intestinal transport of methylmercury and inorganic mercury in various models of Caco-2 and HT29-MTX cells," Toxicology, vol. 311, no. 3, pp. 147-153, 2013.

[52] E. Zubizarreta, E. Zapata, and A. Castiella, "Celiac disease and hemochromatosis," European Journal of Gastroenterology \& Hepatology, vol. 20, no. 6, p. 589, 2008.

[53] D. Barisani, S. Ceroni, S. del Bianco, R. Meneveri, and M. T. Bardella, "Hemochromatosis gene mutations and iron metabolism in celiac disease," Haematologica, vol. 89, no. 11, pp. 12991305, 2004. 


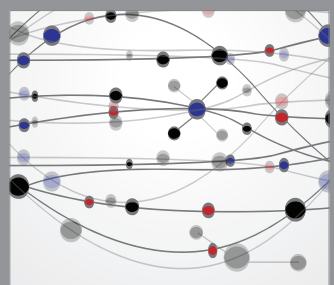

The Scientific World Journal
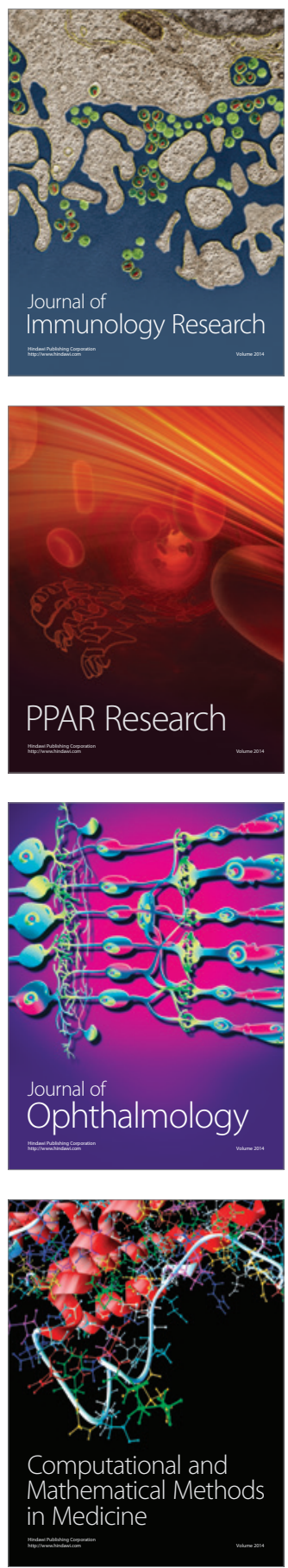

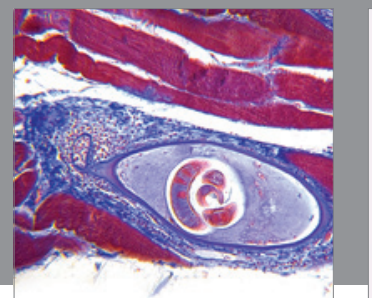

Gastroenterology

Research and Practice
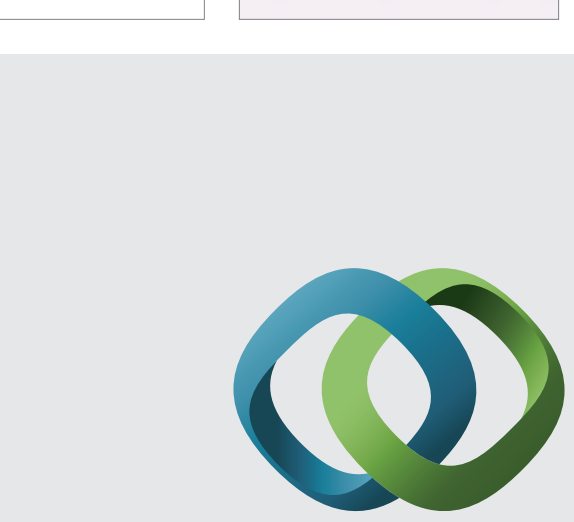

\section{Hindawi}

Submit your manuscripts at

http://www.hindawi.com
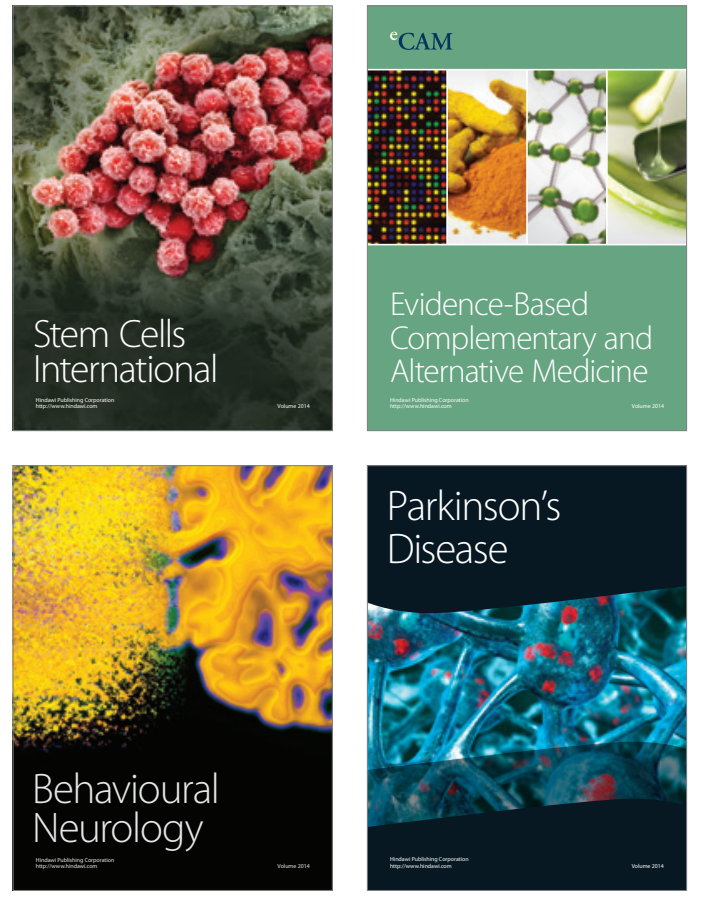
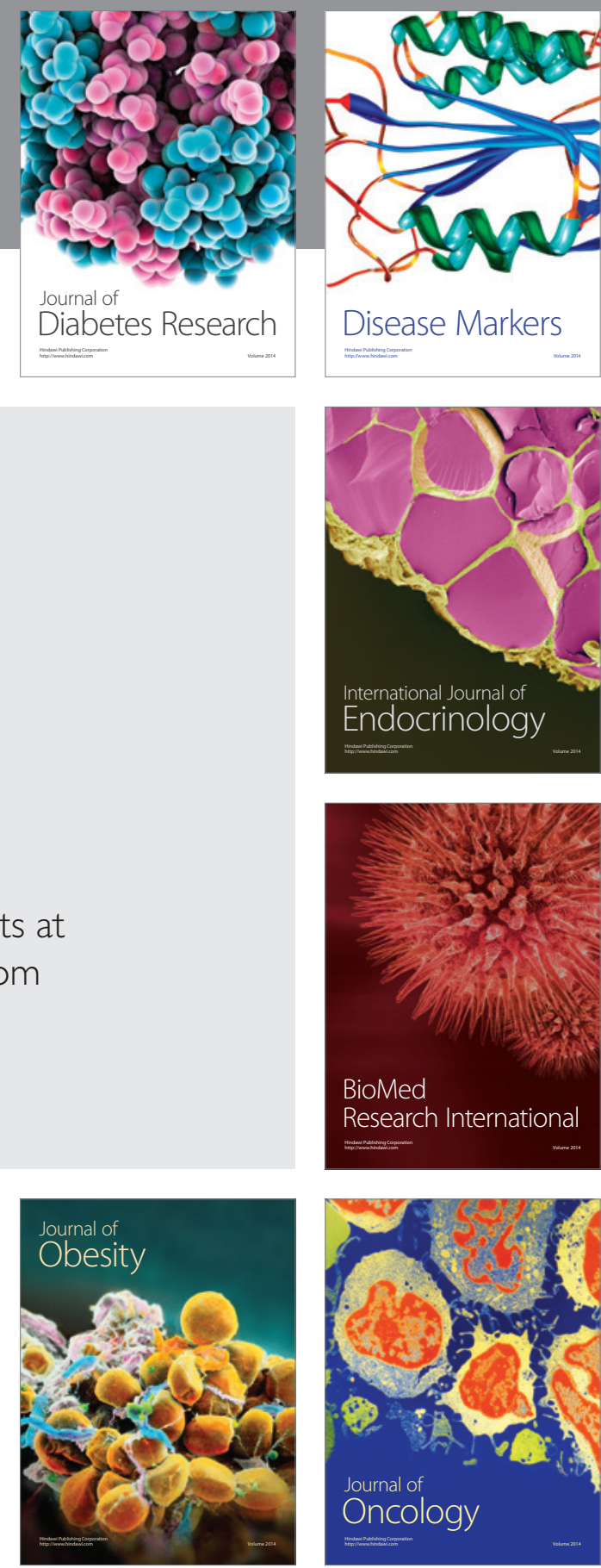

Disease Markers
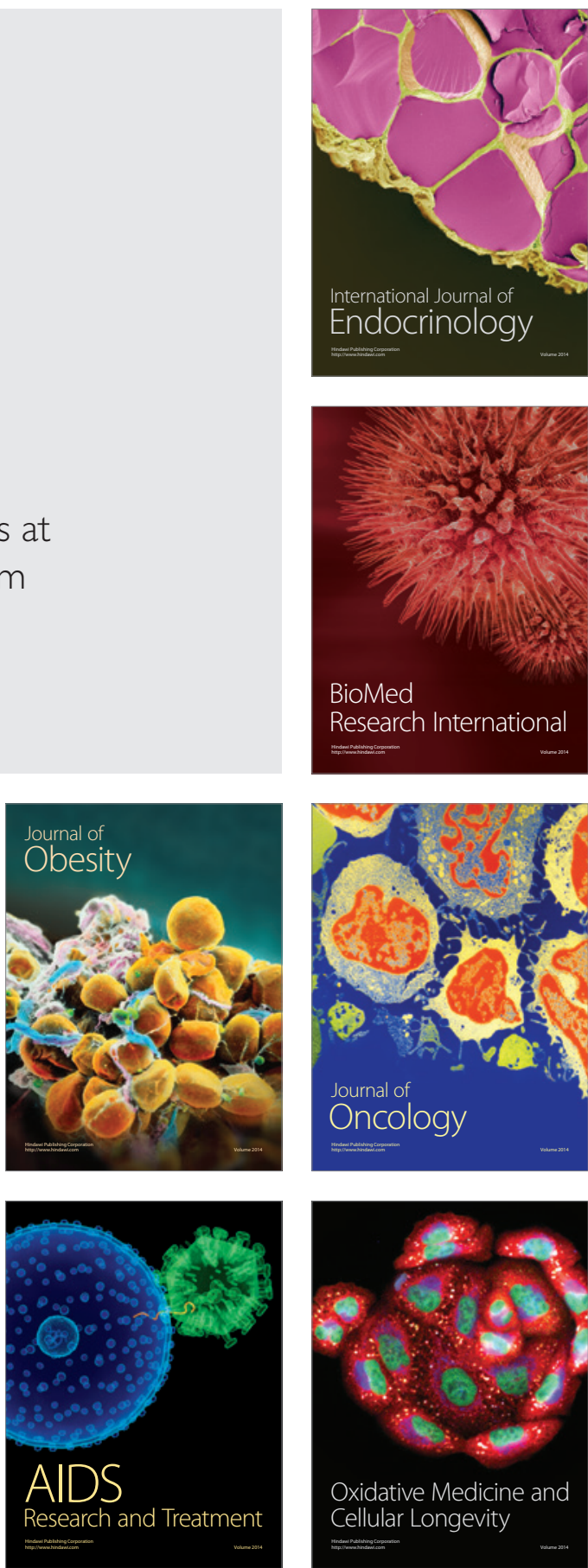